\title{
Review
}

Gheorghe Cruciat, Georgiana Irina Nemeti*, Roxana Popa-Stanila, Andreea Florian and Iulian Gabriel Goidescu

\section{Imaging diagnosis and legal implications of brain injury in survivors following single intrauterine fetal demise from monochorionic twins - a review of the literature}

https://doi.org/10.1515/jpm-2020-0566

Received December 1, 2020; accepted March 18, 2021; published online April 22, 2021

\begin{abstract}
Brain injury of the surviving twin from monochorionic pregnancies following intrauterine fetal demise during the second and third trimesters is a rare but severe complication. Monochorionicity and gestational age at the time of stillbirth seem to be decisive factors in terms of long-term neurologic outcome prediction for the survivor. Magnetic resonance imaging (MRI), diffusion weighted imaging (DWI) in particular, seem to bring the earliest and most accurate diagnosis. Ultrasound detection of brain damage is possible in later stages of fetal brain injury. It is essential to provide early diagnosis and multidisciplinary counsel to the parents to ensure informed decision making. For couples who choose to terminate pregnancy legislation related to late abortion might lead to further distress. Our paper aims to stress the importance of MRI DWI in the evaluation of surviving twins following single intrauterine fetal demise in monochorionic pregnancies and the delicate context of the medical professionals and parents facing this clinical situation, sometimes complicated by legal constraints.
\end{abstract}

Keywords: brain injury; DWI MRI; legal aspects; monochorionic; surviving twin.

\footnotetext{
*Corresponding author: Georgiana Irina Nemeti, Ginecologie I Clinic, Str Clinicilor 3-5, Cluj Napoca 400006, Romania, Phone: +40 723565 256, E-mail: georgiana_nemeti@yahoo.com. https://orcid.org/00000002-8567-1246

Gheorghe Cruciat, Andreea Florian and Iulian Gabriel Goidescu, Obstetrics and Gynecology I, Mother and Child Department, "Iuliu Hațieganu” University of Medicine and Pharmacy, Cluj-Napoca, Romania

Roxana Popa-Stanila, Department of Radiology, "Iuliu Haţieganu” University of Medicine and Pharmacy, Cluj-Napoca, Romania
}

Introduction

Single intrauterine fetal demise (SIUFD) complicates approximately $6 \%$ of twin pregnancies after 20 weeks of gestation (WG) [1]. Data suggest that surviving co-twins of monochorionic (MC) pregnancies have an increased mortality and neurodevelopmental morbidity risk compared to survivors from dichorionic twin pregnancies [2-4]. Monochorionicity is the lead risk factor for adverse pregnancy events, the second most important variable being gestational age at the time of fetal demise. Brain injury of the surviving twin following SIUFD raises diagnostic and management challenges for the obstetrician $[4,5]$. Magnetic resonance imaging (MRI) is superior to ultrasound in the early and detailed description of cerebral lesions [6].

The objective of our work is to summarize the current knowledge regarding prenatal imaging of fetal brain injury in surviving co-twins following SIUFD in MC pregnancies. In the circumstance of predicted fetal neurologic impairment our secondary aim was to highlight the potential legal implications and constraints deriving from the parental decision for late termination of pregnancy (TOP).

\section{Imaging diagnosis of brain lesions and neurologic outcome of the surviving twin}

The increased addressability of assisted reproduction techniques led to an increased incidence of multiples. There is reason to believe the number of MC twins may be influenced by oocyte age, embryo cohort quality, assisted hatching techniques, prolonged embryo cultures [7].

First trimester fetal loss, the "vanishing twin syndrome", is a common accident which happens regardless 
chorionicity and is generally followed by an uneventful course of pregnancy. The demise of one fetus later than 14 WG is believed to prompt significant effects on the continuing pregnancy including neurologic sequelae and cerebral palsy $[8,9]$. In MC twins, SIUFD occurs spontaneously or following an obstetric intervention - selective feticide or fetoscopic laser therapy for twin-to-twin transfusion syndrome (TTTS) [10]. Intrauterine demise of one fetus will lead to an increased risk of adverse events in the survivor twin from MC pregnancies, with fetal brain abnormalities reportedly found in up to $36 \%$ of cases [4].

The increased risk of cerebral damage in survivors following SIUFD generated efforts to identify predictors of neurologic sequalae. There is no gestational age risk stratification regarding the occurrence of cerebral lesions in surviving fetuses following single stillbirth in MC twins [11, 12]. However, judging from previously published reports and supported by our own practice, we may speculate the critical period would be 24-34 WG, when the impact of cerebral lesions is amplified by the immaturity of the fetal brain in the context of prematurity.

Predicting the neurologic outcome of the surviving fetus is the mainstay for ensuring proper parental counseling and informed management planning. It is thus essential to be able to achieve a timely and accurate diagnosis and to discuss fetal prognosis in a multidisciplinary team. Perhaps the main controversy lies in the potential fetal and neonatal capacity to correct and partially heal cerebral lesions, with a good later life prognosis and manageable sequalae.

Prenatal ultrasound is the primary diagnostic imaging method for anomaly screening in pregnancy and the reference standard for neurosonography [13, 14]. It may identify gross atrophic and necrotic-cystic lesions resulting from fetal brain hypoxia-ischemia but has little sensitivity in earlier phases of brain injury. MRI examination of surviving co-twins has been demonstrated to have superior diagnostic accuracy across studies allowing for a timelier and more accurate lesion detection and characterization. Conventional MRI could miss lesions during the first two weeks after SIUFD, with a growing body of literature suggesting the superiority of diffusion weighted imaging (DWI) sequences in the detection of acute ischemic lesions [15-17].

One of the main concerns in pregnancies complicated by SIUFD is our capacity to predict the neurodevelopmental outcome of the surviving fetus with respect to the detected brain lesions and fetal brain maturity at event onset. This is where DWI may play a key role DWI in refining the diagnosis and orienting decision-making. The risk of neurologic impairment is in most cases doubled by that of prematurity.

\section{Types of fetal injury: underlying mechanism and damage site}

The pathophysiologic mechanisms of SIUFD are still under debate. It is believed that temporary hemodynamic fluctuations between twins may lead to coagulopathy and embolic discharge between the chorions, leading to infarctions and cystic changes in the renal, pulmonary, hepatic, splenic and cerebral territories [18]. Another theory accepted is that of acute hemodynamic imbalance caused by hemorrhage from the surviving towards the demised fetus, leading to decreased cerebral perfusion and progressive, ischemic brain injury [19-21].

It appears that different mechanisms of brain injury might lead to different lesion patterns depending on the duration and type of injury, as well as the timing of acute events with respect to the status of brain maturity at the time of insult. Focal/multifocal lesions (nonhemorrhagic or hemorrhagic) are due to thromboembolic events, whereas bilateral injury (asymmetric/most often symmetric) is the consequence of a generally reduced perfusion pressure [22].

There are several theories which aim to clarify the mechanisms of cerebral sequalae of the surviving fetus. Unfortunately, none of them entirely describes the neurologic phenomena which occur and therefore have only didactic value, as long as they do not lead to individualized and prompt management. At the same time, none of these theories is doubled by a proven therapeutic relevance. We must keep in mind that every theory supports a different time-point for lesion occurrence.

Three types of neurologic injury of the surviving fetus were outlined [23]:

(1) Ischemic hypoxic lesions of the white matter which usually occurs in the cerebral area irrigated by the middle cerebral artery and may lead to structural damage (porencephaly, multicystic encephalomalacia, microcephaly, hydranencephaly).

(2) Hemorrhagic lesions, isolated or accompanying ischemic lesions, may lead to post-hemorrhagic hydrocephalus.

(3) Anomalies secondary to vascular disruption which lead to neural tube defects and optic nerve hypoplasia.

White matter injury is more common when SIUFD occurs before $28 \mathrm{WG}$, whereas gray matter damage is identified when fetal demise occurs closer to term [24]. Brain stem and cerebellar lesions are rare and mostly hemorrhagic [21, 25].

Structural lesions diagnosed in utero determined by a stroke are various, depending on the territory irrigated by the obliterated artery as depicted in Table 1. 
Table 1: Classification of cerebral lesions illustrative of stroke according to the obliterated arterial territory (adaptation from Govaert et al. [26]).

\begin{tabular}{|c|c|c|}
\hline Arteries & Vessel & $\begin{array}{l}\text { Resulting cavity (following } \\
\text { fetal stroke) }\end{array}$ \\
\hline $\begin{array}{l}\text { Arterial } \\
\text { cortical type }\end{array}$ & $\begin{array}{l}\text { ACA } \\
\text { MCA } \\
\text { PCA } \\
\text { ICA } \\
\text { Basilar artery } \\
\text { Cerebellar artery }\end{array}$ & $\begin{array}{l}\text { Transmantle porencephaly } \\
\text { Schizencephaly } \\
\text { Hydranencephaly/Hemi- } \\
\text { Hydranencephaly } \\
\text { Multicystic } \\
\text { encephalopathy }\end{array}$ \\
\hline $\begin{array}{l}\text { Arterial perfo- } \\
\text { rator type }\end{array}$ & $\begin{array}{l}\text { ACA } \\
\text { MCA } \\
\text { PCA } \\
\text { Anterior choroidal ar- } \\
\text { tery } \\
\text { Circle of Willis }\end{array}$ & $\begin{array}{l}\text { Ventral porencephaly } \\
\text { Porencephaly due to } \\
\text { arterial perforator stroke } \\
\text { Paraventricular white } \\
\text { matter cyst }\end{array}$ \\
\hline $\begin{array}{l}\text { Brain stem } \\
\text { arteries }\end{array}$ & $\begin{array}{l}\text { PCA } \\
\text { Basilar artery } \\
\text { Circle of Willis }\end{array}$ & $\begin{array}{l}\text { Absence of pons, midbrain } \\
\text { disconnection }\end{array}$ \\
\hline $\begin{array}{l}\text { Spinal cord } \\
\text { arteries }\end{array}$ & $\begin{array}{l}\text { Anterior spinal artery } \\
\text { Posterior spinal ar- } \\
\text { teries Adamkiewicz } \\
\text { artery }\end{array}$ & \\
\hline
\end{tabular}

ACA, anterior cerebral artery; MCA, middle cerebral artery; PCA, posterior cerebral artery; ICA, internal carotid artery.

According to the data published by Govaert and collaborators, the middle cerebral artery is the site of almost $50 \%$ of cerebral strokes, followed by the internal carotid artery (ICA), anterior cerebral artery, posterior cerebral artery and choroid artery [26].

\section{Imaging studies of suspected brain injury - techniques and timing of investigation}

\section{Ultrasound of suspected brain injury}

Brain sequelae of the surviving twin after SIUFD may be difficult to identify by conventional imaging techniques. Ultrasound is considered to be the reference standard for imaging the fetal brain [13]. 2D, 3D and Doppler US, performed to transabdominally and endovaginally, according to the gestational age and fetal lie remain the handiest, widely used and most economic investigations of fetal structure and well-being [14].

The ability to identify brain lesions of surviving co-twins by ultrasound was first reported in the 90s together with the first attempts to predict neurologic sequelae [27, 28]. It was initially thought that ultrasound could serve as a screening tool for the detection of cerebral injury of the surviving twin following SIUFD, but several authors advocated its limitations [5, 29-31]. Ultrasound detects either discrete changes such as ventriculomegaly, subarachnoid space enlargement, periventricular echogenicity or, major sequelae of fetal brain hypoxia-ischemia [32-34]. Destructive lesions of the brain are visualized by sonography in the stage of malacic cysts, when the shape of cerebral hemispheres is altered by atrophic changes, that is 3 weeks from the acute event [34]. There are also technical difficulties of identifying parenchymal cerebral trauma due to the acoustic shadowing of skull bones. Neurosonography of the surviving fetus performed early, in the first 10-14 days following single fetal demise may overlook certain neurologic lesions. Therefore, ultrasound is best not employed alone for establishing the diagnosis of ischemia/hemorrhage or to distinguish uncomplicated ventricular/subarachnoid space enlargement from cases with associated brain damage [32].

\section{MRI - timing and specific findings}

It is clear that, even though neurosonography performed by expert examiners is the first line prenatal imaging tool for twin pregnancies [14, 35] in the case of survivors from single stillbirth in MC twins it either only identifies markers of fetal injury or detects cerebral lesions later during follow-up. MRI has been shown to have an increased detection and timelier diagnostic accuracy for brain lesions, especially the DWI sequence, however, the heterogeneity of research partly compromises these findings.

MRI is expensive, less accessible, it requires experienced examiners and high-resolution machines, however it should be included in the evaluation standard of surviving fetuses following SIUFD in order to refine diagnosis and estimation of neurodevelopmental prognosis. There is currently no consensus regarding the timing of MRI with respect to the period elapsed from cotwin demise, technical specifications of the MRI machine, whether the DWI sequence should be included in the protocol by default, the necessity of repeated examinations.

MRI has enhanced soft-tissue contrast compared to ultrasound, richer details of cerebral architecture displaying the precise extension of lesions into the cerebral parenchyma. At the same time, MR allows for the detection of cortical lesions, which are close to the skull bones [19]. However, conventional T1, T2, fluid attenuated inversion recovery (FLAIR) sequences detect only sequelar lesions and not acute ischemic injury during the same period [36, 37]. Given the long waiting interval until the materialization of cerebral lesions by ultrasound and conventional MRI, as 
well as the fact that many times the parents opt for TOP before the identification of lesions, the use of the DWI sequence may shorten the time to diagnosis [19]. The principle at the basis of the diffusion sequence is the measurement of the Brownian movement of particles in a voxel of tissue. This type of movement is reduced in tissues with rich cellularity, such as tumors or when cellular swelling is present, such as cytotoxic edema in acute ischemias [38, 39].

The magnitude of diffusion of water molecules on a cellular scale is objectively measured by the apparent diffusion coefficient (ADC), using MRI with DWI at different $\mathrm{b}$ values (a factor that reflects the strength and timing of the gradients used to generate diffusion-weighted images). ADC values are displayed as a parametric map, automatically calculated by the software. Regions of interest (ROIs) can be drawn on the ADC map and the measurements within a ROI can be recorded. The ADC of tissues is expressed in units of $\mathrm{mm}^{2} / \mathrm{s}$.

There are several studies estimating the brain maturation across different gestation ages, with reproducible ADC measurements [40-44]. Abnormal low ADC values can be indicative of acute ischemic injury, reflecting cytotoxic ischemia $[45,46]$ or, while high ADC values are indicative of chronic ischemic changes, like vasogenic edema with astrogliosis of the cerebral parenchyma [46].

There may be a role fetal brain MRI volumetry and diffusion tensor imaging (DTI) scalar measurements in the evaluation and prognostic counseling of SIUFD survivors in MC twins, but this is yet to be evaluated. Volumetry may refine the diagnosis of delay in brain growth and increase the accuracy of predicted neurologic impairment [32].

The timing of MRI following single stillbirth is somewhat controversial, with several authors advocating for an interval between 1 and 3 weeks as the best moment to accurately identify and classify cerebral injury. According to Conte et al., MR examinations should be performed within 1 week from the fetal demise, while Righini et al. and Hoffman et al. consider that it should be performed at 2 and respectively 3 weeks after the SIUFD in order to allow the identification of cavitation and atrophic cerebral lesions [15, $19,47]$. It has been speculated that MRI performed too soon after cotwin death may lead to underdiagnosis of evolving ischemic injury or malformations of cortical development [32]. However, the adjunct of DWI to the MRI investigation allows for the discrete acute ischemic injuries to be identified before volume loss, cystic encephalomalacia or malformations of cortical development become evident.

In cases of MC twin pregnancies with signs of TTTS, cerebral injury can be conspicuous on MRI alone, unrelated to the Quintero stage in up to $10 \%$ of cases, as shown by the authors of a recent study (2020) before a planned procedure like selective fetoscopic laser photocoagulation. It is difficult to appreciate if there may be cerebral changes visible only to MRI prior to SIUFD, since this can be a sudden event and MRI is not routinely performed for screening of MC twin pregnancies without any US indication of fetal distress and in the absence of a planned procedure [48].

The use of DWI is unanimously accepted as superior with respect to the precocity of diagnosis. DWI signal changes occurring in cerebral ischemia may be detected early, in the first 30 min from the vascular obliteration as stated by Nicolini et al. [21] or, within the first day of co-twin demise according to several other authors [17, 29, 33]. Its usefulness is restricted to the first week after the death of the co-twin, interval after which pseudo normalization occurs [49]. It has been demonstrated in animal models that the ADC value of DWI decreases within a few minutes from ischemia onset given that diffusion of water molecules within the tissue is deterred by cellular swelling in the extracellular space, both of which are the consequence of progressive cytotoxic edema [50,51].

Several authors reported cases of survivors following SIUFD at different gestational ages, most of which had no signs of cerebral damage on ultrasound and injury was diagnosed by MRI, especially DWI. Righini et al. reported the case of a 24 weeks surviving fetus from MC twin pregnancy where DWI located the lesion in the frontal periventricular white matter and the anterior part of the corpus callosum. Follow-up MRI performed two weeks later found a cyst of the septum pellucidum cavity (Table 2) [45].

A prospective cohort study which enrolled $34 \mathrm{MC}$ twin pregnancies complicated by SIUFD (spontaneous or following laser coagulation of anastomoses for TTTS) found cerebral lesions of the surviving fetus in nine cases. Two cases exhibited unspecific ultrasound changes (one increased middle cerebral artery peak systolic flow and one fetal hydrops) and cerebral injury diagnosis was achieved by DW MRI (Table 2) [19].

In another study performed by Hoffman et al. in 3 out of 6 cases of spontaneous SIUFD where cerebral lesions were diagnosed by DWI, there were no suggestive ultrasound findings. In 3 out of 10 cases of fetal demise following laser coagulation for TTTS, there were cerebral lesions in the survivor. None of these cases had predictive ultrasound signs, all three cases were identified by DW. In 3 out of 18 cases of selective fetal reduction by bipolar coagulation, DWI diagnosed one case of severe, bilateral ischemia and two cases of germinal matrix hemorrhage and focal changes in the basal ganglia. Ultrasound was normal in all of these fetuses [19].

A retrospective observational study which enrolled 434 cases of MC multiple pregnancies with SIUFD found 42 
Table 2: Reports comparing ultrasound examination to conventional MRI and DWI.

\begin{tabular}{|c|c|c|c|}
\hline & Ultrasound & T2 MRI & DWI \\
\hline \multicolumn{4}{|l|}{ Righini 2007} \\
\hline \multicolumn{4}{|l|}{ Hoffmann 2013} \\
\hline \multirow{9}{*}{$\begin{array}{l}\text { Group A: Spontaneous IUFD } \\
(\mathrm{n}=6) . \\
\text { Group B: Laser ablation } \\
(\mathrm{n}=10) \text {. } \\
\text { Group C: Selective reduction } \\
(\mathrm{n}=18) .\end{array}$} & Normal US; normal Doppler & Normal & Severe findings of acute ischemic lesions. \\
\hline & $\begin{array}{l}\text { Normal US; fetal anemia - elevated peak } \\
\text { systolic velocity in the MCA }\end{array}$ & Brain edema & Severe findings of acute ischemic lesions \\
\hline & $\begin{array}{l}\text { Ascites and thickened fetal skin; fetal ane- } \\
\text { mia - elevated peak systolic velocity in the } \\
\text { MCA }\end{array}$ & Normal & Normal \\
\hline & Normal US; normal Doppler & Normal & $\begin{array}{l}\text { Severe temporal lobe } \& \text { periventricular } \\
\text { infarcts of the co-twin }\end{array}$ \\
\hline & Normal US; normal Doppler & $\begin{array}{l}\text { Detects injury } \\
3 \text { weeks later }\end{array}$ & GM bleeding \\
\hline & Normal US; normal Doppler & $\begin{array}{l}\text { Confirmed the injury } \\
3 \text { weeks later }\end{array}$ & GM bleeding \\
\hline & Normal US; normal Doppler & $\begin{array}{l}\text { Detects injury } \\
3 \text { weeks later }\end{array}$ & $\begin{array}{l}\text { Bilateral cerebral ischemia } 1 \text { day after the } \\
\text { procedure }\end{array}$ \\
\hline & Normal US; normal Doppler & Normal & GM bleeding \\
\hline & Normal US; normal Doppler & Normal & Focal changes in the basal ganglia \\
\hline \multicolumn{4}{|l|}{ Weisz 2014} \\
\hline Group A: one twin survived & Normal US; normal Doppler & Normal & GM bleeding \\
\hline following the procedure $(n=8)$ & Normal US; normal Doppler & Normal & GM bleeding \\
\hline Group B: both twin survived & Normal US; normal Doppler & Hypointense signal & GM bleeding \\
\hline following the procedure & Normal US; normal Doppler & Normal & GM bleeding \\
\hline \multirow[t]{4}{*}{$(n=22)$} & Normal US; normal Doppler & $\begin{array}{l}\mathrm{GM} \text { and lateral } \\
\text { ventricle bleeding }\end{array}$ & - \\
\hline & Normal US; normal Doppler & Normal & $\begin{array}{l}\text { One fetus with diffuse ischemic white } \\
\text { matter changes }\end{array}$ \\
\hline & $\begin{array}{l}\text { Small hyperechoic foci adjacent to Sylvian } \\
\text { fissure in the right hemisphere }\end{array}$ & Normal & $\begin{array}{l}\text { Infarction in posterior half of one hemi- } \\
\text { sphere demonstrated by DWI and ADC }\end{array}$ \\
\hline & $\begin{array}{l}\text { Ascites resolved ( } 25-28 \text { WG); ven- } \\
\text { triculomegaly ( } 28 \text { WG); normal Doppler }\end{array}$ & GM bleeding & $\begin{array}{l}\text { Diffuse scattered areas of hyperintensity } \\
\text { in both hemispheres with low signal in } \\
A D C \text { map }\end{array}$ \\
\hline \multicolumn{4}{|l|}{ Robinson 2017} \\
\hline \multirow{5}{*}{$\begin{array}{l}\text { Spontaneous cotwin demise } \\
(\mathrm{n}-10)\end{array}$} & $\mathrm{n}=7 / 10$ & \multicolumn{2}{|l|}{$n=7 / 10$} \\
\hline & Normal US; normal Doppler & \multicolumn{2}{|l|}{ Normal } \\
\hline & Normal US; normal Doppler & \multicolumn{2}{|c|}{ Bilateral occipital cortical infarction, polymicrogyria } \\
\hline & Ventriculomegaly & \multicolumn{2}{|c|}{$\begin{array}{l}\text { Ventriculomegaly, intraventricular hemorrhage, delayed } \\
\text { sulcation }\end{array}$} \\
\hline & $\begin{array}{l}\text { Increased extra-axial space, periventricular } \\
\text { echogenicity, asymmetrical ventricles } \\
(<10 \mathrm{~mm})\end{array}$ & \multicolumn{2}{|c|}{$\begin{array}{l}\text { Asymmetrically widened extra-axial spaces, decreased hemi- } \\
\text { spheric size, asymmetrical ventricles }<10 \mathrm{~mm}\end{array}$} \\
\hline Demise post laser ablation for & $n=6 / 8$ & \multicolumn{2}{|l|}{ Normal } \\
\hline \multirow[t]{3}{*}{$\operatorname{TTTS}(\mathrm{n}=8)$} & Normal US; normal Doppler & & \\
\hline & Normal US; normal Doppler & \multicolumn{2}{|c|}{ Dural sinus thrombosis } \\
\hline & Normal US; normal Doppler & \multicolumn{2}{|c|}{$\begin{array}{l}\text { Cystic lesion left frontal lobe (connatal cyst or small germinal } \\
\text { matrix infarct) }\end{array}$} \\
\hline \multicolumn{4}{|l|}{ Aertsen 2020} \\
\hline Two cases of SIUFD survivors & Normal US & \multicolumn{2}{|l|}{ Focal polymicrogyria } \\
\hline in MC twins with TTTS & \multicolumn{3}{|c|}{ Bilateral cortical atrophy secondary to bleeding } \\
\hline
\end{tabular}

US, ultrasound; ADC, apparent diffusion coefficient; DWI, diffusion-weighted imaging; GM, germinal matrix; MCA, middle cerebral artery; TTTS, twin to twin transfusion syndrome. 
cases of cerebral parenchymal lesions [34]. They recorded 14 cases of focal cerebral non-hemorrhagic lesions and nine of encephalomalacia. A detailed pathology examination performed on these fetuses noted that 35 cases were ischemic, and seven hemorrhagic. The authors underlined that the cortex is the main site of cerebral injury in the surviving twin, while the stalk and cerebellum are rarely involved. The latter lesions are more commonly of hemorrhagic than ischemic nature [24, 25].

Jelin et al. published a similar research in 2008, proving the superiority of MRI over US in detecting intracranial abnormalities in twins following SIUFD. The authors mention having used a 1.5 T MRI and T2 sequences, but no DWI sequence. Most of the cases in their series reported demise following TTTS or twin reversed arterial perfusion (TRAP), only $14 \%$ had no additional diagnosis [52].

Weisz and collaborators studied a cohort of 30 twin pregnancies with TTTS and fetoscopic laser coagulation. They analyzed the risk of neurologic implications by DW and T2W MRI 24-96 $\mathrm{h}$ after the procedure and follow-up MRI at 32 weeks. The authors certified that DW MRI may demonstrate the presence of neurologic lesions immediately after the procedure, while conventional MRI and ultrasound may miss certain early changes (Table 2) [19].

Robinson et al. reported an analysis of prenatal brain MRI findings compared to neurosonography in complicated MC pregnancies. The study did not offer information to distinguish between conventional MRI and DWI sequences. MRI detected brain lesions missed by US in 2 out of 10 survivors following spontaneous cotwin demise and 2 out of 8 survivors of demise post laser ablation for TTTS. MRI examinations were performed more than two weeks after fetal demise [32].

A study performed by Aertsen in 2020 evaluated the usefulness of prenatal MRI in the detection of brain damage in MC twins complicated by TTTS following in utero surgery. They reported two cases of cerebral lesions from 13 pregnancies complicated by SIUFD, one of which had been picked up by US, while the second was diagnosed only after MRI. The authors do not offer details regarding the timespan from fetal demise to fetal MRI, nor do they specify whether the DWI sequence was used in these cases [53].

Kocaoglu et al. published their work regarding the correlation of the TTTS staging, cerebral damage detected by MRI and fetal outcome. The authors found that MRI DWI is superior to conventional MRI with respect to the speed of detection and sensitivity to diagnose brain lesions [48].

The vast majority of studies regarding the value fetal MRI in general and that of the DWI sequence in the assessment of fetal brain injury used MR machines with the field strength of $1.5 \mathrm{~T}$. Regarding the DWI sequence, not all technical characteristics are consistently provided by the authors, except the b values, with a max of $600-700$ or 1,000. Fetal MR imaging at $3 \mathrm{~T}$ is comparable to that of field strength of $1.5 \mathrm{~T}$, but the higher image resolution and SNR, mean that finer structures and lesions can be delineated $[54,55]$.

ADC values are not consistently reported, for example Kocaoglu et al. considered they would be inaccurate because of the heterogeneity of scanning parameters, fetal gestational age and motion artifacts, and the inherent challenges of placing reproducible ROIs on the small fetal brain.

The continuingly increased incidence of twin pregnancies as a result of the growing addressability of assisted reproduction techniques calls for a common standard of care in cases of SIUFD as a redoubtable complication in MC pregnancies. This raises the need that all such cases should be reported and preferably included in multi-centered, international trials to enhance patient numbers and reach statistic relevance.

Judging from all the studies published on this topic so far, we can safely conclude that MRI is a valuable tool in the evaluation of cerebral damage of surviving fetuses post SIUFD in MC pregnancies, especially the DWI sequence. Guidelines regarding $\mathrm{MC}$ twin pregnancy monitoring should include the indication for MRI DWI in the event of SIUFD in order to be able to accurately estimate the outcome of the surviving twin.

\section{Fetal and neonatal neurodevelopmental prognostic factors}

Survivor cotwin neurodevelopmental outcome is the focus of management in MC pregnancies complicated by single fetal demise. Decision making should be prompted by existing prognostic evidence.

However, studies published so far are few and quite heterogeneous, present case reports or case series over large periods of time, MRI timing and examination protocols differ, pregnancy management varies according to the gestational age at lesion detection/type of lesion/multidisciplinary team counsel/parental choice, there is great subjectivity in every case management (obstetrician, counseling team, parents), pediatric neurologic follow-up is scarcely reported in cases with live births.

According to Petterson et al. who cites data from the 1980s marked in the Western Australian cerebral palsy register, surviving twins following SIUFD had a prevalence of cerebral palsy of 96.2 per 1,000 which is 15 times higher than for twin pregnancies with both live-born 
fetuses $(6.4 / 1,000)$ and 60 times higher than for singletons $(1.6 / 1,000)$ [56]. Other studies report a 20-fold, and respectively 4-fold increased risk of cerebral impairment for the liveborn co-twin after intrauterine single fetal demise compared with the general twin risk [49].

A study conducted by Bonellie and collaborators concluded there was an increased risk of cerebral palsy in the surviving twin of 6.3 odds ratio (95\% CI 3.1-12.8) compared to twin pregnancies where both twins survived [57]. The same results were confirmed by Luu and Vohr who reported a probability of cerebral palsy of $9.5 \%$ (95\% CI 3.6$19.6 \%)$ in the surviving twin, compared to only $1.8 \%$ (95\% CI 1.3-2.4) when both fetuses survived [58].

A systematic review and metanalysis performed in 2011 by Hillman et al. found a five-fold increased risk of neurodevelopmental morbidity in survivors following single twin demise in MC compared to dichorionic pregnancies.

A study performed in 2015 reported a case series of 11 twin pregnancies complicated by single fetal demise [59]. Survivors with normal MRI examinations had a normal neonatal neurologic outcome after being evaluated using the Denver Developmental Screening Test II. Only one of three fetuses diagnosed with cerebral lesions by MRI proved a normal neurologic development at follow-up. There were authors who stated that ischemic injuries can be diagnosed early using DWI MRI and affirmed that lesions are progressive. The long-term neuro-cognitive development of these fetuses could not be tracked because of three fetuses with progressive lesions one died in utero and the other two underwent selective termination [50].

Lanna et al. published in 2020 the data from a retrospective study enrolling $78 \mathrm{MC}$ pregnancies complicated by SIUFD, 14 of which had cerebral lesions (5 uncomplicated, 9 complicated by TTTS or selective growth restriction). Gestational age at diagnosis was 20-26 WG and 32 WG in one case. Ten cases were identified by ultrasound and confirmed by conventional MRI - of these eight pregnancies were terminated and those who delivered had mild and respectively severe neurological sequalae. Of the four cases with normal ultrasound, one had abnormal cerebral MR imaging and was terminated, another with normal MRI delivered and had a good prognosis, in another two cases MRI was not performed, delivery was achieved at 29.5 and $32 \mathrm{WG}$ and the neonates had mild and respectively severe neurological sequalae [60].

Other authors argue that an immediate decision should not be made solely on the basis of the initial lesions diagnosed on the MRI, especially since the current data is insufficient to outline an accurate neuro-fetal prognosis. A recent case report asserts that the early ischemic changes identified by DWI MRI can only be transient and if reperfusion occurs, a persistent injury is uncommon, recommending a repeat MRI two-three weeks after SIUFD [51]. These observations were generated from the resemblance with the pathophysiology of stroke which states that neuronal damage depends mainly on the decreased cerebral blood flow and the duration of ischemia before reperfusion. Lesions which cause cytotoxic edema are quickly detected by DWI, but they will disappear if reperfusions occur or worsens if ischemia persists [59].

The decision to terminate pregnancy should be reserved for those fetuses with unquestionably severe ischemic cerebral injury, precluding germinal matrix or basal ganglia damage which are categorized as minor lesions.

\section{Ethical considerations regarding late TOP}

The purpose of reaching an accurate diagnosis is to establish a management protocol and the optimal treatment to follow. In the case of brain damaged survivor twin following SIUFD, there are no immediate valid treatment options for the pathology per se. The clinician is faced with the following possible management choices: (1) TOP - feticide given the gestational age of occurrence of this pathology and (2) continuing pregnancy until the threshold of fetal prematurity or reaching term.

Once cerebral damage is certified in the surviving twin following SIUFD a multidisciplinary team comprising the maternal-fetal medicine specialist, the neonatologist, pediatric neurologist/neurosurgeon informs the couple regarding the expected neurodevelopmental outcome of the fetus. It is the task of this committee to establish whether the couple should be counseled to continue or interrupt pregnancy. However, the final decision belongs to the parents. The high emotional impact and the lack of solid data regarding the outcome of their offspring beyond the neonatal period make any logic medical substantiation impossible.

Both physicians and families pressured to reach sometimes critical decisions might attribute excessive importance to imaging findings, the more so as an exact correlation of anatomic and neurologic lesions is not well established as yet.

We may safely state that the long-term outcome of surviving twins following SIUFD is still poorly predictable but carries a high risk of cerebral injury and cerebral palsy. Studies conducted to date regarding the neurodevelopmental outcome and future parent-child relationship of these infants are too scarce to draw firm conclusions. 
It might be argued that time to diagnosis of brain lesions is of no capital importance since it does not change the fetal outcome and in many cases does not alter management. However, in countries with legislative constraints regarding late TOP, early confirmation of neurologic morbidity allows for parental freedom of decision. Should the couple decide for TOP couples are forced to look for solutions in foreign countries with permissive legislations.

Should parents opt for continuation of pregnancy, they must be counseled with regard to the possibility of iatrogenic premature delivery which increases the severity of the neurologic prognosis. There are authors who report that couples may opt for TOP even in cases with minor abnormalities with no clinical correlation and refuse even waiting for further imaging evaluation.

Sometimes, following the decision to terminate pregnancy, juridical difficulties arise since feticide is not legally accepted in all countries. There are countries where such medical procedures are allowed, but in others, TOP over a certain gestational age threshold falls under the incidence of penal law. At the same time, medical recommendation has a different weight in different countries. Sometimes, the social-cultural background and religious beliefs may have an equal share in the decision-making process. All these considerations lead to further parental distress, financial burden and the so-called "medical tourism". As far as the European continent is concerned, the European Union fortunately provides the legal framework which allows couples to travel to countries with access to late TOP. This leads to a different type of bias, since it is the financial status of the couple which allows them to go through with their choice, or not.

\section{Conclusions}

SIUFD in MC pregnancies might result in cerebral injury of the surviving co-twin. Some cases are diagnosed prenatally, others during the early postpartum period. A better understanding of the intimate mechanisms leading to neurologic injury, early imaging diagnosis and correlation between intrauterine cerebral lesions and neonatal cognitive and neuro-psychologic impairment should offer clinicians and patients more information in order to decide pregnancy management. An early and accurate diagnosis could influence parental choice. Extreme actions such as feticide should however be carefully balanced, as decisions based only on the DW MRI examination are delicate. So far, limited experience has accumulated with this tool for the detection of prenatal brain injury.
Parental decision to terminate pregnancy must be made after rigorous medical counseling by an interdisciplinary committee regarding the potential fetal outcome. The psychologic impact and the diversity of legislative rulings in each country will influence this decision.

Research funding: None declared.

Author contributions: All authors have accepted responsibility for the entire content of this manuscript and approved its submission.

Competing interests: Authors state no conflict of interest.

\section{References}

1. Ong SSC, Zamora J, Khan KS, Kilby MD. Prognosis for the co-twin following single-twin death: a systematic review. BJOG An Int J Obstet Gynaecol 2006;113:992-8.

2. Oldenburg A, Rode L, Bødker B, Ersbak V, Holmskov A, Jørgensen FS, et al. Influence of chorionicity on perinatal outcome in a large cohort of Danish twin pregnancies. Ultrasound Obstet Gynecol 2012;39:69-74.

3. D’Antonio F, Thilaganathan B, Dias T, Khalil A, Bahamie A, Bhide A, et al. Influence of chorionicity and gestational age at single fetal loss on risk of preterm birth in twin pregnancy: analysis of STORK multiple pregnancy cohort. Ultrasound Obstet Gynecol 2017;50: 723-7.

4. Hillman SC, Morris RK, Kilby MD. Co-twin prognosis after single fetal death: a systematic review and meta-analysis. Obstet Gynecol 2011;118:928-40.

5. Schwartz N, Keeler SM, Fishman S, Timor-Tritsch IE. Neurosonography to detect brain injury in a surviving monochorionic twin after demise of its co-twin. J Clin Ultrasound 2009;37:165-7.

6. Nielsen BW, Scott RC. Brain abnormalities in fetuses: in-utero MRI versus ultrasound. Lancet 2017;389:483-5.

7. Mateizel I, Santos-Ribeiro S, Done E, Van Landuyt L, Van De Velde $\mathrm{H}$, Tournaye $\mathrm{H}$, et al. Do ARTs affect the incidence of monozygotic twinning? Hum Reprod 2016;31:2435-41.

8. Shipp TD, Bromley B, Benacerraf B. The ultrasonographic appearance and outcome for fetuses with masses distorting the fetal face. J Ultrasound Med 1995;14:673-8.

9. Pharoah POD. Neurological outcome in twins. Semin Neonatol 2002;7:223-30.

10. Barigye O, Pasquini L, Galea P, Chambers H, Chappell L, Fisk NM. High risk of unexpected late fetal death in monochorionic twins despite intensive ultrasound surveillance: a cohort study. PLoS Med 2005;2:0521-7.

11. Senat $M-V$. Mort fœtale in utero et grossesse gémellaire. J Gynécol Obstet Biol Reprod 2009;38:S100-3.

12. Walsh CA. Early 2nd trimester fetal demise in a monochorionic twin pregnancy: a cautionary tale. Australas J Ultrasound Med 2015;18:78-81.

13. Jarvis D, Mooney C, Cohen J, Papaioannou D, Bradburn M, Sutton $A$, et al. A systematic review and meta-analysis to determine the contribution of $\mathrm{mr}$ imaging to the diagnosis of foetal brain abnormalities in utero. Eur Radiol 2017;27:2367-80. 
14. Paladini D, Malinger G, Pilu G, Timor-Trisch I, Volpe P. The MERIDIAN trial: caution is needed. Lancet 2017;389:2103.

15. Righini A, Salmona S, Bianchini E, Zirpoli S, Moschetta M, Kustermann $A$, et al. Prenatal magnetic resonance imaging evaluation of ischemic brain lesions in the survivors of monochorionic twin pregnancies. Report of 3 cases. J Comput Assist Tomogr 2004;28:87-92.

16. Glenn OA, Quiroz EM, Berman JI, Studholme C, Xu D. Diffusionweighted imaging in fetuses with unilateral cortical malformations and callosal agenesis. Am J Neuroradiol 2010;31: 1100-2.

17. Deveer R, Engin-Ustun Y, Mert I, Sarikaya E, Bozkurt S, Deveer M, et al. Twin pregnancies with single fetal death: analysis of 38 cases. Fetal Pediatr Pathol 2013;32:71-5.

18. Cleary-Goldman J, D'Alton M. Management of single fetal demise in a multiple gestation. Obstet Gynecol Surv 2004;59: 285-98.

19. Hoffmann C, Weisz B, Yinon Y, Hogen L, Gindes L, Shrim A, et al. Diffusion MRI findings in monochorionic twin pregnancies after intrauterine fetal death. Am J Neuroradiol 2013;34:212-6.

20. Okamura K, Murotsuki J, Tanigawara S, Uehara S, Yajima A. Funipuncture for evaluation of hematologic and coagulation indices in the surviving twin following co-twin's death. Obstet Gynecol 1994;83:975-8.

21. Nicolini U, Poblete A. Editorial Single intrauterine death in monochorionic twin pregnancies. Ultrasound Obstet Gynecol 1999;14:297-301.

22. Conte G, Righini A, Griffiths PD, Rustico M, Lanna M, Mackie FL, et al. Brain-injured survivors of monochorionic twin pregnancies complicated by single intrauterine death: MR findings in a multicenter study. Radiology 2018;288:582-90.

23. Sato H, Murata H, Sato K, Kawaharamura K, Hamanishi S, Hirose $M$. Encephalomalacia in surviving twin after single fetal death diagnosed at 18 weeks of gestation in monochorionic twin pregnancy. Am J Case Rep 2013;14:341-4.

24. O'Donoghue K, Rutherford MA, Engineer N, Wimalasundera RC, Cowan FM, Fisk NM. Transfusional fetal complications after single intrauterine death in monochorionic multiple pregnancy are reduced but not prevented by vascular occlusion. BJOG An Int J Obstet Gynaecol 2009;116:804-12.

25. Van Klink JMM, Van Steenis A, Steggerda SJ, Genova L, Sueters M, Oepkes D, et al. Single fetal demise in monochorionic pregnancies: incidence and patterns of cerebral injury. Ultrasound Obstet Gynecol 2015;45:294-300.

26. Govaert P, Ramenghi L, Taal R, De Vries L, Deveber G. Diagnosis of perinatal stroke I: definitions, differential diagnosis and registration. Acta Paediatr 2009;98:1556-67.

27. Fusi L, Gordon H. Twin pregnancy complicated by single intrauterine death. Problems and outcome with conservative management. BJOG An Int J Obstet Gynaecol 1990; 97:511-6.

28. Yoshida K, Matayoshi K. A study on prognosis of surviving cotwin. Acta Genet Med Gemellol (Roma) 1990;39:383-8.

29. Mackie FL, Morris RK, Kilby MD. Fetal brain injury in survivors of twin pregnancies complicated by demise of one twin: a review. Twin Res Hum Genet 2016;19:262-7.

30. Griffiths PD, Sharrack S, Chan KL, Bamfo J, Williams F, Kilby MD. Fetal brain injury in survivors of twin pregnancies complicated by demise of one twin as assessed by in utero MR imaging. Prenat Diagn 2015;35:583-91.
31. Simonazzi G, Segata M, Ghi T, Sandri F, Ancora G, Bernardi B, et al. Accurate neurosonographic prediction of brain injury in the surviving fetus after the death of a monochorionic cotwin. Ultrasound Obstet Gynecol 2006;27:517-21.

32. Robinson A, Teoh M, Edwards A, Fahey M, Goergen S. Fetal brain injury in complicated monochorionic pregnancies: diagnostic yield of prenatal MRI following surveillance ultrasound and influence on prognostic counselling. Prenat Diagn 2017;37: 611-27.

33. Larroche JC, Droullé P, Delezoide AL, Narcy F, Nessmann C. Brain damage in monozygous twins. Biol Neonate 1990;57:261-78.

34. Langer B, Boudier E, Gasser B, Christmann D, Messer J, Schlaeder $G$. Antenatal diagnosis of brain damage in the survivor after the second trimester death of a monochorionic monoamniotic cotwin. Fetal Diagn Ther 1997;12:286-91.

35. Khalil A, Rodgers M, Baschat A, Bhide A, Gratacos E, Hecher K, et al. ISUOG Practice Guidelines: role of ultrasound in twin pregnancy. Ultrasound Obstet Gynecol 2016;47:247-63.

36. Paladini D, Quarantelli M, Sglavo G, Pastore G, Cavallaro A, D'Armiento MR, et al. Accuracy of neurosonography and MRI in clinical management of fetuses referred with central nervous system abnormalities. Ultrasound Obstet Gynecol 2014;44: 188-96.

37. Pistorius LR, Hellmann PM, Visser GHA, Malinger G, Prayer D. Fetal neuroimaging: ultrasound, MRI, or both?. Obstet Gynecol Surv 2008;63:733-45.

38. Goidescu IG, Nemeti G, Caracostea G, Eniu DT, Chiorean A, Pintican $R$, et al. The role of imaging techniques in the diagnosis, staging and choice of therapeutic conduct in pregnancy associated breast cancer. Med Ultrason 2019;21:336-43.

39. Muller TB, Haraldseth O, Jones RA, Sebastiani G, Godtliebsen F, Lindboe CF, et al. Combined perfusion and diffusion-weighted magnetic resonance imaging in a rat model of reversible middle cerebral artery occlusion. Stroke 1995;26:451-8.

40. Cannie M, De Keyzer F, Meersschaert J, Jani J, Lewi L, Deprest J, et al. A diffusion-weighted template for gestational age-related apparent diffusion coefficient values in the developing fetal brain. Ultrasound Obstet Gynecol 2007;30:318-24.

41. Schneider MM, Berman JI, Baumer FM, Glass HC, Jeng S, Jeremy RJ, et al. Normative apparent diffusion coefficient values in the developing fetal brain. Am J Neuroradiol 2009; 30:1799-803.

42. Cartry C, Viallon V, Hornoy P, Adamsbaum C. Diffusion du cerveau fœtal normal: Limites et espoirs. J Radiol 2010;91:561-6.

43. Boyer AC, Gonçalves LF, Lee W, Shetty A, Holman A, Yeo L, et al. Magnetic resonance diffusion-weighted imaging: reproducibility of regional apparent diffusion coefficients for the normal fetal brain. Ultrasound Obstet Gynecol 2013;41:190-7.

44. Sartor A, Arthurs O, Alberti C, Belarbi N, Tilea B, Boizeau P, et al. Apparent diffusion coefficient measurements of the fetal brain during the third trimester of pregnancy: how reliable are they in clinical practice? Prenat Diagn 2014;34:357-66.

45. Righini A, Kustermann A, Parazzini C, Fogliani R, Ceriani F, Triulzi F. Diffusion-weighted magnetic resonance imaging of acute hypoxic-ischemic cerebral lesions in the survivor of a monochorionic twin pregnancy: case report. Ultrasound Obstet Gynecol 2007;29:453-6.

46. Baldoli C, Righini A, Parazzini C, Scotti G, Triulzi F. Demonstration of acute ischemic lesions in the fetal brain by diffusion magnetic resonance imaging. Ann Neurol 2002;52:243-6. 
47. Mackie FL, Rigby A, Morris RK, Kilby MD. Prognosis of the co-twin following spontaneous single intrauterine fetal death in twin pregnancies: a systematic review and meta-analysis. BJOG An Int J Obstet Gynaecol 2019;126:569-78.

48. Kocaoglu M, Kline-Fath BM, Calvo-Garcia MA, Zhang B, Nagaraj UD. Magnetic resonance imaging of the fetal brain in monochorionic diamniotic twin gestation: correlation of cerebral injury with ultrasound staging and survival outcomes. Pediatr Radiol 2020;50:1131-8.

49. Scher Al, Petterson B, Blair E, Ellenberg JH, Grether JK, Haan E, et al. The risk of mortality or cerebral palsy in twins: a collaborative population-based study. Pediatr Res 2002;52:671-81.

50. Van Der Toorn A, Syková E, Dijkhuizen RM, Vořǐšek I, Vargová L, Škobisová E, et al. Dynamic changes in water ADC, energy metabolism, extracellular space volume, and tortuosity in neonatal rat brain during global ischemia. Magn Reson Med 1996;36:52-60.

51. Shrot S, Hoffmann C, Katorza E. Reversible parenchymal ischemic injury on fetal brain MRI following fetoscopic laser coagulation-implication on parental counseling. Radiol Case Rep 2020;15:1369-72.

52. Jelin AC, Norton ME, Bartha Al, Fick AL, Glenn OA. Intracranial magnetic resonance imaging findings in the surviving fetus after spontaneous monochorionic cotwin demise. Am J Obstet Gynecol 2008;199:398.e1-e5.

53. Aertsen M, Van Tieghem De Ten Berghe C, Deneckere S, Couck I, De Catte L, Lewi L. The prevalence of brain lesions after in utero surgery for twin-to-twin transfusion syndrome on third-trimester MRI: a retrospective cohort study. Eur Radiol 2020. https://doi. org/10.1007/s00330-020-07452-x.

54. Weisstanner C, Gruber GM, Brugger PC, Mitter C, Diogo MC, Kasprian G, et al. Fetal MRI at 3T-ready for routine use? Br J Radiol 2017;90:20160362.

55. Priego G, Barrowman NJ, Hurteau-Miller J, Miller E. Does 3T fetal MRI improve image resolution of normal brain structures between 20 and 24 weeks' gestational age? Am J Neuroradiol 2017;38: 1636-42.

56. Petterson B, Nelson KB, Watson L, Stanley F. Twins, triplets, and cerebral palsy in births in Western Australia in the 1980s. Br Med J 1993;307:1239-43.

57. Bonellie S, Currie D, Chalmers J. Comparison of risk factors for cerebral palsy in twins and singletons. Dev Med Child Neurol 2005;47:587-91.

58. Luu TM, Vohr B. Twinning on the brain: the effect on neurodevelopmental outcomes. Am J Med Genet Part C Semin Med Genet 2009;151C:142-7.

59. Jatzko B, Rittenschober-Böhm J, Mailath-Pokorny M, Worda C, Prayer D, Kasprian G, et al. Cerebral lesions at fetal magnetic resonance imaging and neurologic outcome after single fetal death in monochorionic twins. Twin Res Hum Genet 2015;18:606-12.

60. Lanna MM, Consonni D, Faiola S, Izzo G, Scelsa B, Cetin I, et al. Incidence of cerebral injury in monochorionic twin survivors after spontaneous single demise: long-term outcome of a large cohort. Fetal Diagn Ther 2020;47:66-73. 